\title{
Building personas from phenomenography: a method for user-centered design in education
}

\author{
Tra Huynh
}

\author{
Department of Physics, University of Washington Bothell, Bothell, \\ Washington, USA
}

Adrian Madsen and Sarah McKagan

American Association of Physics Teachers, College Park, Maryland, USA, and

\author{
Eleanor Sayre
}

Department of Physics, Kansas State University, Manhattan, Kansas, USA

\begin{abstract}
Purpose - Personas are lifelike characters that are driven by potential or real users' personal goals and experiences when interacting with a product. Personas support user-centered design by focusing on real users' needs. However, the use of personas in educational research and design requires certain adjustments from its original use in human-computer interface design. This paper aims to propose a process of creating personas from phenomenographic studies, which helps us create data-grounded personas effectively.

Design/methodology/approach - Personas have features that can help address design problems in educational contexts. The authors compare the use of personas with other common methodologies in education research, including phenomenology and phenomenography. Then, this study presents a sixstep process of building personas using phenomenographic study as follows: articulate a design problem, collect user data, assemble phenomenographic categories, build personas, check personas and solve the design problem using personas. The authors illustrate this process with two examples, including the redesign of a professional development website and an undergraduate research program design.

Findings - The authors find that personas are valuable tools for educational design websites and programs. Phenomenography can productively help educational designers and researchers build sets of personas following the process the authors propose.
\end{abstract}

(C) Tra Huynh, Adrian Madsen, Sarah McKagan and Eleanor Sayre. Published by Emerald Publishing Limited. This article is published under the Creative Commons Attribution (CC BY 4.0) licence. Anyone may reproduce, distribute, translate and create derivative works of this article (for both commercial and non-commercial purposes), subject to full attribution to the original publication and authors. The full terms of this licence may be seen at http://creativecommons.org/licences/by/4.0/ legalcode

Portions of this work appeared in an earlier form in the first author's doctoral dissertation (Huynh, 2020).

The authors are greatly indebted to Sandy Martinuk for introducing us to the persona methodology, to their studies' participants, and to Paul Irving for conducting the original interviews of the physics students. Jeremy Smith and Kim Coy are their copy-editors. This material is based upon work supported by the National Science Foundation under Grant Nos. DUE-1726479/1726113, and the Kansas State University Department of Physics. Any opinions, findings, and conclusions or recommendations expressed in this material are those of the author(s) and do not necessarily reflect the views of the National Science Foundation.

\section{Received 7 December 2020 Revised 16 May 2021 1 June 2021 Accepted 14 June 2021}

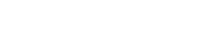




\section{ILS $122,11 / 12$ \\ Originality/value - The use and method of personas in educational contexts are scarce and vague. Using the example contexts, the authors provide educational designers and researchers a clear method of creating personas that are relatable and applicable for their design problems.}

Keywords Personas, User-centered design, Educational design problem, Higher education, Methodology, Faculty development, Undergraduate research

Paper type Conceptual paper

\section{Introduction}

The field of education research has rapidly brought numerous insights into learning, teaching and professional development. Meanwhile, the design remains an important step to bring these ideas to life and bridge the gap between research and practice. The effective design puts an emphasis on exploring user perspective and experience. The term "user" refers to anyone that the product or service is designed. In a university context, the "user" could be faculty, students, academic staff, administrators, etc. The focus of this paper is the application of a user-centered design tool called personas from the interface design context to education. Personas enable designers to center the needs of users by providing evidencebased, relatable, person-like constructs to design for. Therefore, personas can support effective design and research in education. Our work aims to illustrate a method to implement personas to approach design problems-based around educational user needs and goals [1].

User-centered design as a design approach has been widely adopted in humancomputer interface design as an attempt to develop programs or products that are shaped by the end users (Norman, 2013). Even though it is still common for designers to pretend to be users and imagine the product features that they think users would like, designers differ from real users in their technical skills, knowledge, expertise and usage goals. Furthermore, designers and product builders face the tension between the ease of coding and design issues and the product's power and usability. Consequently, in designer-centered or technology-focused design, many products turn out to poorly serve the needs of real users because they are based on the designers' perspectives and experiences and not the users. In recent decades, user-centered design has emerged to promote product usability and user satisfaction.

The user-centered design focuses on understanding the whole user experience with products via the user's characteristics, tasks and environments. This understanding allows designers to prioritize various types of users and create products that fulfill those diverse requirements and expectations. One of the key principles in building a user-centered design is organizing the products around the users' goals, tasks and abilities, as well as the way users process information and make decisions (Endsley, 2016). The focus on different characteristics leads to different approaches and analytical tools, which vary in how and when to involve users in the design process.

Here, we briefly discuss some common approaches and analytical tools under the usercentered design umbrella, including personas (Figure 1). Emotional design (Norman, 2013) and empathic design (Crossley, 2003) are two approaches to user-centered design that focus on users' emotional states. Meanwhile, activity-centered design (ACD) attempts to understand users by focusing primarily on understanding the activities that people perform with given sets of tools which, in turn, influences the design of those tools. Even though ACD properly addresses human behavior, it does not really address why a user is performing an activity or a task, which is often viewed as a drawback of this approach (Cooper, 2007). 


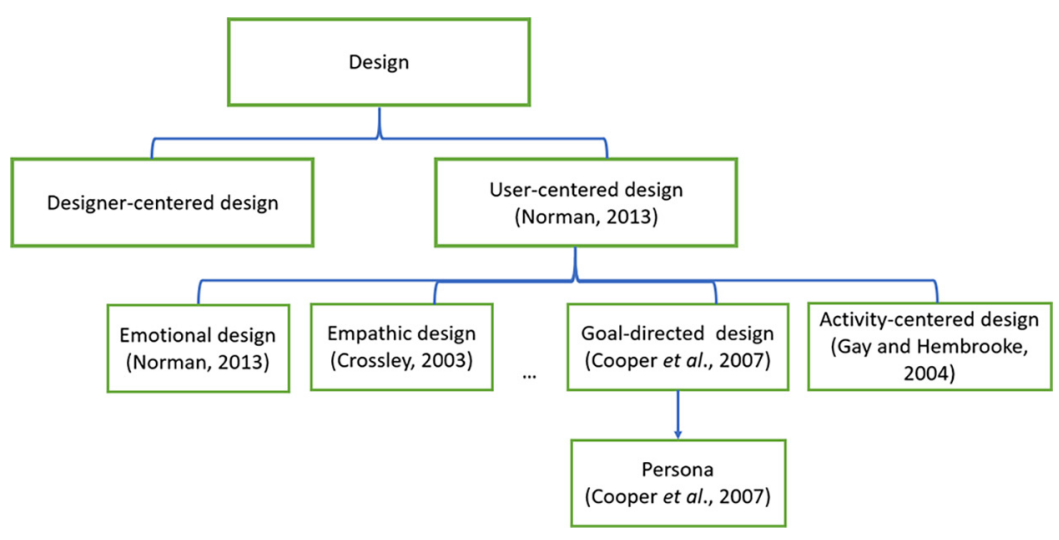

User-centered design in education

691

Instead of focusing on users' activity, Cooper (1999) proposes a design approach called goaldirected design, which prompts designers to focus on people's goals and attitudes in the early stage of the design process to devise design solutions that users find useful, powerful and pleasurable. Cooper also devised personas as an analytic tool to support the goaldirected approach by providing a language to represent and discuss the rich and dynamic behavior of users. The method of using personas to represent potential users as lifelike characters have become standard practice for user experience designers (Pruitt and Grudin, 2003).

In education, the user-centered design process coupled with the method of personas can help designers to empathize with and understand users' goals. For example, personas support instructional design that centers learners' needs, including university instruction development (Salomão et al., 2015; Kozar and Miaskiewicz, 2009) and informal learning in the workplace (Maier and Thalmann, 2010). Personas have also been used in educational contexts beyond instructional design including library research (Zaugg and Rackham, 2016) and faculty professional development (Zagallo et al., 2019; Madsen et al., 2014, 2019). The method of personas is useful outside of these contexts as well. For example, an undergraduate program advisor might create a set of personas describing a variety of undergraduate experiences and trajectories to help advise course flows that best meet students' goals and needs. Or a curriculum designer could develop personas of faculty who are potential implementers of the materials they are developing so that they can ensure the materials meet faculty needs.

In this work, we focus on personas as a qualitative research methodology that educators and researchers can use to study users and build non-curricular products. We discuss personas via two examples of educational problems of practice as follows: supporting faculty professional development (Madsen et al., 2019) and engaging undergraduate students in research (Huynh et al., 2020). Even though the procedure and technique of generating personas can be found in numerous design instructions, there is still a paucity in persona use and its methodology description in education research. Furthermore, the difference between interface design and education research and design requires designers and researchers to make adjustments in educational contexts. For example, as personas involve some fictitious elements and may not be reproducible, it may be challenged to be regarded as scientific (Nielsen, 2013). Therefore, we hope to offer the science and art of personas, presenting an explicit and principled method to create and use personas in the 


\section{ILS}

$122,11 / 12$

\section{2}

context of educational research. We propose a method of creating personas largely based on the approach commonly used in interface design, but with modifications that involve completing a phenomenographic analysis as part of the process. We choose to do so via two example design problems that educators may find relatable, useful and applicable for their own design problems. While our prior papers have focused on the personas themselves, this paper focuses on the methodology of generating and using personas.

\section{Overview of personas as a design tool}

\subsection{How personas serve design}

Originating from the goal-directed perspective, personas are lifelike characters that are driven by potential or real users' personal goals and embody their experiences when using products (Cooper, 1999; Blomkvist, 2007). Personas are not a description of individuals or average information of specific groups of users. They are combined patterns of users' behavior and motivations, where the rich information of an amalgamation of users is synthesized into a set of user archetypes or personas (Madsen et al., 2014). These personas have some fictional details added, such as names, images and background information, to make them more concrete and lifelike. Even though personas are not real people, they represent real users throughout the design process. Just like scientists build models to represent and simplify physical systems for further focusing on investigation and exploration, a set of personas is a powerful tool to represent and communicate users' rich and complicated behavior, motivations and attitudes. The key strengths of personas are encapsulating the critical characteristics of users into humanlike constructs in such a way that designers and stakeholders can understand, remember and relate to while leaving out details about individual users that are idiosyncratic and irrelevant to the design problem (Goodwin, 2002).

Personas work because people can predict another person's behavior by understanding their mental state (Grudin and Pruitt, 2002; Pruitt and Grudin, 2003). We use our knowledge and experience to draw inferences, make predictions and form expectations. When fully engaged with personas, designers can effortlessly project them onto new situations and extrapolate how different contexts could affect their behaviors. For example, designers can easily engage and empathize with a specific persona in the statement "Diego prefers to use resources from his own department because he is trying to enculturate into his new departmental practices." In contrast, it can be difficult to engage with and act on a statistical statement such as "Only 30\% of the interviewed faculty with access to departmental resources look for resources from elsewhere." Building personas pushes designers to engage with and think about the users' perspectives, treat them as real and prioritize their needs over the ease of the design process. Personas, therefore, can help with bolstering the usability of the products.

Personas also help designers to draw focus on a specific range of users and to promote communication and consensus among designers and stakeholders (Cooper, 1999; Cooper et al. 2007; Grudin and Pruitt, 2002; Long, 2009; Pruitt and Adlin, 2010). One design cannot satisfy all users, and personas, no matter how carefully conceived, will not perfectly cover all conceivable users. Instead, building personas help us explicitly discuss who is being designed for and target specific features, rather than creating every possible feature and ending up with usability problems (Pruitt and Grudin, 2003; Blomkvist, 2007). The art of persona creation also lies in its ability to push designers to be aware of and put aside their biases and stereotypes. Designers can purposefully craft personas that celebrate the diversity of users and potential users, instead of only representing the small set of users present in their data. For example, if you interviewed more men than women, you could still represent an equal number of men and women in your persona set (Mulder and Yaar, 2006).

Personas, as user archetypes, are an especially powerful way to represent research subjects with a marginal risk of exposing their identities. Classic research methodologies, such as 
phenomenology and ethnography, face a much higher risk of exposing identities when presenting and reporting confidential individuals' rich and accurate details to stakeholders. Classically, we can increase the size of the anonymity set, either by sampling more people or by removing some identifiers. However, personas present a different path, which is well-suited for many different kinds of problems that classical solutions are not as good at. In this work, we propose using phenomenographic study to craft personas, which we argue makes the experience feel relatable and representable to users while still protecting their identities.

\subsection{How personas fit into the design flow}

In a user-centered design process, crafting personas is usually one of the first tasks after collecting user data. Personas, as a user research and analysis tool, support and cooperate with other design tools such as scenarios. A scenario is a story with a plot and a sequence of actions and events built around actors - personas - who have distinctive goals. In the perspective, that users' goals drive their behavior, designers figure out each personas' actions in specific scenarios, which are goals that users might have when interacting with the product, coupled to actions that they would take to achieve their goals. Using personas to shape scenarios means the scenarios are personalized for specific types of users and better reflect the specific users' experience. In return, these persona-based scenarios clarify and give life to our personas, leading toward meaningful design solutions (Pruitt and Grudin, 2003).

\section{Personas versus phenomenology case study and phenomenography}

Personas address different questions than traditionally asked in education research, and therefore, might or might not be useful in all cases. In this section, we briefly compare the methodology of building personas with two of the common methodologies in education research, phenomenologic case studies and phenomenography, to illuminate differences among them and suggest the kinds of problems that personas are well suited to solve.

Phenomenologic case studies (Creswell, 2007) explore rich details of small numbers of anonymous individuals with a focus on the nature of their experience (Table 1). Phenomenology qualitatively describes individuals' experiences and phenomena. In presenting rich details about individuals, there is a risk of revealing the participants' identity even if those identities are anonymous because the uniqueness of the individual creates an anonymity set too small to protect their identity. For example, in a case study of a "female physics faculty member," readers from her department can probably identify her. On the other hand, personas are synthesized from real people's behavior constructs and do not represent any one individual. Therefore, personas are great at protecting participants' identities.

Phenomenologic case studies are valuable in deeply understanding individuals, but it is difficult for designers to use these descriptions of individuals to solve design problems. Many of the details are specific to an individual and do not generalize to other similar users. If designers base their designs on case studies of individuals, they will likely end up with a product that only meets the needs of those individuals. Personas are built from larger collections of participants, leaving out idiosyncratic details of individuals, which leads to design solutions that are more broadly useful.

On the other hand, phenomenography investigates a variety of qualitatively different ways that people experience some activities or artifacts (Marton, 1986) (Table 1). Phenomenographic studies collect ideas about the experiences of a large number of participants; the results of this method are lists of categories within broader themes describing the participants' experiences. For example, you might have a list of the various motivations your users discussed in interviews and a list of the various attitudes they described. Phenomenography describes the variation in interview participants' experiences around different themes but does not track the 


\section{ILS \\ $122,11 / 12$}

\begin{tabular}{|c|c|c|c|}
\hline & Phenomenology & Phenomenography & Persona \\
\hline Characteristic features & $\begin{array}{l}\text { Studying an } \\
\text { individual's human } \\
\text { experience, focusing } \\
\text { on the nature of the } \\
\text { phenomenon }\end{array}$ & $\begin{array}{l}\text { Studying the } \\
\text { qualitatively different } \\
\text { ways people experience } \\
\text { a phenomenon }\end{array}$ & $\begin{array}{l}\text { Building goals has } \\
\text { driven semi-fictitious } \\
\text { user archetypes from } \\
\text { the amalgamation of } \\
\text { real users }\end{array}$ \\
\hline Exemplary research question & $\begin{array}{l}\text { How does an } \\
\text { instructor notice and } \\
\text { flip a student's frame } \\
\text { of reasoning? }\end{array}$ & $\begin{array}{l}\text { How do faculty } \\
\text { approach changes in } \\
\text { teaching? }\end{array}$ & $\begin{array}{l}\text { Who are the users of } \\
\text { PhysPort and how are } \\
\text { they using the resources } \\
\text { there? }\end{array}$ \\
\hline Data collection & $\begin{array}{l}\text { Many possible sources } \\
\text { (observation, } \\
\text { interview, human } \\
\text { artifact with the focus } \\
\text { on the phenomenon, i. } \\
\text { e. experience) }\end{array}$ & $\begin{array}{l}\text { Semi-structured } \\
\text { interviews with focused } \\
\text { questions }\end{array}$ & $\begin{array}{l}\text { Many possible sources } \\
\text { (interview, survey, site } \\
\text { log, etc., with the focus } \\
\text { on users' goals, attitude } \\
\text { and interaction with the } \\
\text { designed product) }\end{array}$ \\
\hline Expected outcomes & $\begin{array}{l}\text { A rich, complete and } \\
\text { accurate qualitative } \\
\text { description or } \\
\text { interpretation of an } \\
\text { individual's } \\
\text { experience }\end{array}$ & $\begin{array}{l}\text { An emerged list of } \\
\text { themes and categories of } \\
\text { descriptive ways in } \\
\text { which many } \\
\text { participants experience } \\
\text { something }\end{array}$ & $\begin{array}{l}\text { A set of personas } \\
\text { (including name, } \\
\text { pictures and goal- } \\
\text { directed description) }\end{array}$ \\
\hline Evaluation method & $\begin{array}{l}\text { Thickness of } \\
\text { description, } \\
\text { participant validation, } \\
\text { triangulated } \\
\text { description }\end{array}$ & $\begin{array}{l}\text { Seeking for saturation of } \\
\text { themes and variation } \\
\text { within themes }\end{array}$ & $\begin{array}{l}\text { Seeking for the set of } \\
\text { personas that expand } \\
\text { the user sample }\end{array}$ \\
\hline Weaknesses & $\begin{array}{l}\text { Generalization issue } \\
\text { due to dependence on } \\
\text { the participant's point } \\
\text { of view and articulate } \\
\text { skills } \\
\text { Overfitting the data }\end{array}$ & $\begin{array}{l}\text { Emergent themes } \\
\text { dependent on the } \\
\text { interplay between the } \\
\text { researchers and } \\
\text { research }\end{array}$ & $\begin{array}{l}\text { Sensitive to users' } \\
\text { changeable goals, } \\
\text { sensitive to design } \\
\text { questions and contexts. } \\
\text { May miss out atypical } \\
\text { users because it does not } \\
\text { seek saturation in } \\
\text { sampling data }\end{array}$ \\
\hline Iconic citation & Polkinghorne (1989) & Marton (1986) & Cooper et al. (2007) \\
\hline
\end{tabular}

Table 1.

Persona, phenomenology and phenomenography in comparison

\section{4}

Exemplary research question

Many possible sources

(observation,

interview, human

artifact with the focus

the phenomenon, 1 .

A rich, complete and

accurate qualitative

description or

interpretation of an

Thickness of

description,

triangulated

description

of view and articulate

skills
Studying the qualitatively different

ways people experience approach changes in

Semi-structured interviews with focused questions

\section{An emerged list of} which many themes and variation within themes

Emergent themes dependent on the lay between the researchers and research
Building goals has the amalgamation of real users they using the resources there? $\log$, etc., with the focus on users' goals, attitude designed product) A set of personas including name, pictures and goaldirected description) xpand

Sensitive to users' changeable goals, sensitive to design users because it does not saturation in Cooper et al. (2007)

experiences of individual users across themes. For example, phenomenography may present a list of results about participants' motivations and another list about their challenges, but it does not connect an individual user's motivations to their challenges. This disconnect means that it cannot serve the design process, whereby motivations and challenges must be linked at the individual level. However, phenomenography can be used as the basis to create personas. This idea will be further explained in the next section.

\section{Personas built on the results of phenomenography}

Generally, the process of creating personas consists of as follows: collecting and analyzing user data; finding the motivational and behavioral patterns on which personas emerge; and bringing personas to life (Cooper, 2007). The data collecting methods for building personas vary from quantitative methods based on user surveys or site logs (Mulder and Yaar, 2006) to qualitative methods based on in-depth user interviews and ethnographic observation (Cooper et al., 2007; Goodwin, 2002). Rapid ethnography is a modification of ethnography 
that is more timely and affordable to build personas (Maier and Thalmann, 2010; Stefaniak, 2020). Although there is no clear consensus on the optimal method to build personas, some designers (Cooper et al., 2007; Goodwin, 2002) argue that qualitative data, specifically ethnographic interviews, is an inexpensive and effective way to deeply understand users.

After gathering user data, designers can draft personas using variables, affinity diagrams or a system of coordinates (Nielsen, 2013). Although these methods have worked well within their contexts, they become difficult to apply to qualitative data that are common in educational contexts. Cooper represents variables (such as attitude, aptitude and challenges) on separate axes. On each axis he plots users in relation to each other, looking for emergent behavioral patterns across all axes. For example, Cooper maps user behavior from service-oriented to price-oriented, giving each user a single value along with this axis (Cooper et al, 2007). However, we experience that for some qualitative data, the categories within each theme can be characteristically different without an inherent ordering. For example, categories in the theme of motivation for change can include solving big problems in the department, becoming a better teacher or having fun with teaching. Moreover, one person can be present in multiple categories within one theme; one faculty member can have multiple motivations. Using phenomenographic analysis, which we propose, can avoid forcing user experiences into orderly patterns. Our study expands the current body of work around methods to find user patterns to create data-grounded goal-directed personas.

We argue that persona generation should be based on phenomenographic studies for two reasons. First, a phenomenography develops a list of short, concise and significant variations among users' experiences. Building personas from phenomenographic data makes it easier to ensure our cast of personas fully accounts for the significant variation in experiences, which could be easily washed out in other qualitative methods. Our personas, therefore, better reflect the important features of real people. Building personas from phenomenographic results can be more time consuming than building personas from raw interview data because it involves extra analysis to generate the phenomenography. However, spending more time with the data during the phenomenographic study helps researchers turn their visceral feelings into data-grounded decisions.

One might argue that there is no better way to fully reflect real people than by directly describing them. However, that is not the purpose of personas. Personas are user archetypes: we want them to be as humanlike as possible, but we also need to foreground the features which are salient to our design problem. Therefore, working from a phenomenographic study helps us to avoid drowning in details that do not help solve the design problem. These superfluous details tend to draw our focus away from the design itself and toward the description and narrative of real stories or real people instead. We suggest that an effective first step in building a set of personas is a phenomenographic study. In the next sections, we will introduce two example sets of personas for two design problems and illustrate how we used phenomenography to generate these personas.

\section{Example personas: faculty and undergraduate researchers}

\section{Methodology}

We present our methodology of building personas step by step via an example process of building faculty personas to address a design problem of a faculty professional development website - PhysPort. In general, we start with articulating the design problem and collecting user data. Next, we carry out a phenomenographic study where we assemble categories of user experience and features. Then, we construct personas by synthesizing the categories into human-constructs and check the personas' validity.

We also briefly discuss how we are going to use the personas for future design. Designing, including building personas, is an iterative process. We hope to provide 


\section{ILS}

$122,11 / 12$

educational designers with the underpinnings of the process so that they are confident in developing useful and reliable sets of personas.

\subsection{Articulate design problem}

At the beginning of any design, it is very important for the group of stakeholders, researchers and designers to discuss and specify a design problem that aligns with the ultimate mission of the organization. A clearly defined design problem helps clarify and guide user research, including choosing users to study, as well as design research methodologies.

PhysPort (http://physport.org) is a website that supports physics faculty in implementing research-based teaching and assessment in their classes (McKagan et al., 2020; Strubbe et al., 2020). PhysPort was created piecemeal, as various pieces of the site were funded and now the PhysPort team is redesigning the site to make it more coherent, as well as more usable for its intended audience, college physics faculty. The design problem for the PhysPort redesign is as follows: How can physics faculty find what they need on PhysPort to try out new things in their teaching? The PhysPort team uses personas to understand and prioritize potential users and then they create scenarios that meet the needs of those users. Clearly articulating the design problem helps us determine the range of users whose data we want to collect. For example, experienced faculty seeking new resources have radically different goals and decision-making processes from new faculty seeking materials for their first time. Effective design trajectories for these two types of users are different. Therefore, in this case, we focus on faculty that have been making or attempting to make changes in their teaching, rather than those who are teaching for the very first time.

\subsection{Collect user data}

There are several data collecting methodologies. While interviews and surveys are better at clarifying user goals, motivations and attitudes, other methodologies such as site log analysis or eye tracking can reveal users' actual behavior and interaction with the product (Mulder and Yaar, 2006). To support user-centered design with a better understanding of and empathy for users, designers should interact with users during data collection, instead of just relying on quantitative survey or site log analysis data or watching an interview someone else did with the users. In this case, we collected qualitative interviews with 23 physics faculty (7 women/16 men) from diverse US University contexts to build faculty goaldirected personas.

The interviews focused on how physics faculty approach changes to their teaching; a secondary aim was to develop personas of potential PhysPort users. We conducted phenomenographic semi-structured interviews remotely using video and audio; each lasted for about $1 \mathrm{~h}$. During each interview, we asked the participant to describe their instructional practices as follows: how they approach their teaching; what kinds of changes they were making to their teaching this term; their motivation to make changes; their assessment practices around the change; resources that they use; how they use those resources; and challenges they experienced with their teaching. We also asked about their background, departmental culture and how they collaborate with others around teaching.

After each interview, two team members who participated in the interview each wrote down the key points they noticed individually and later discussed these. After several of these discussions, we updated the interview protocol to probe themes around motivation and development of teaching practices more carefully for subsequent interviews. Each interview was video recorded and transcribed for analysis using a professional transcription 
service. Upon completion, the video and transcripts of the interviews became the focus of our phenomenographic analysis.

\subsection{Assemble phenomenographic categories}

Before building personas, we carry out a phenomenographic study that aims at exploring and assembling a variety of human experiences. The creativity of the work of the phenomenographic study lies in the focused and principled observation of this emergent information. The process of generating a phenomenographic study starts with identifying emergent themes. We acknowledge that these themes are directly and indirectly predetermined by our goal for the design. We initially use our judgment to decide what types of information about users are important enough to characterize users and their interaction with our design, based on which we design our semistructured interview protocols. After collecting the data, we examine the set of interviews to refine and finalize the list of themes such that they are also important from interviewees' experiences and perspectives. Semi-structured interviews allow us to explore further users' complex and personalized experiences, and therefore, give us more information to ground our choice of emergent themes. When these themes are identified, researchers carry out iterative analyzes, going back to the data and reexamining each real person to probe the full breadth of each theme. Figure 2 describes this process in detail (Zohrabi Alaee et al., 2020).

For example, when investigating faculty approaches to change, our emergent themes included as follows: motivations for trying a new idea, attitudes toward change, types of ideas to implement, how they know if the new idea is working and what resources faculty use to find new ideas. These themes are varied among all the interviewees. For example, in the theme of motivation for changing, we found our interviewees' motivations included wanting to benefit their students; wanting to integrate with their departmental culture; and wanting a more enjoyable teaching experience. Motivation for teaching and making changes has a huge influence on other behaviors, which is consistent with motivation theories (Ryan and Deci, 2000) and the goal-directed perspective of personas (Blomkvist, 2007). Once we have the phenomenographic results as themes and sub-categories describing each theme, we can start creating personas.
User-centered design in education

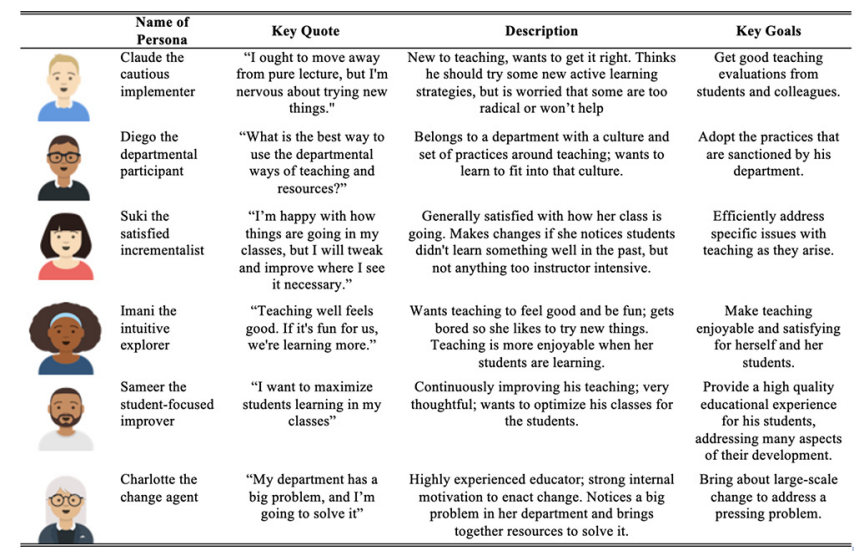

Figure 2. Faculty personas 


\section{ILS \\ $122,11 / 12$}

698

Table 2.

Illustrative table to create personas

\subsection{Build personas}

The process of building personas is comprising two stages. The first stage is developing the personas using the phenomenographic themes and the variations within those themes. The second stage is making the personas feel alive with person-like features. When embodying phenomenographic categories into personas, the creative task is to make sure the themes and the vast variations within those themes are distributed throughout the cast of personas such that they emerge as plausible mixes of traits. One conducive format is a tabular form as shown in Table 2.

We sketch out personas by filling in their characteristics using the categories found in the phenomenographic study. We prioritize goals and motivations by filling in the column of "Goal and Motivation" first, has different goals and motivations result in vastly different personas. Therefore, the goal and motivation of each persona will help us set a tone for their characters later. Further, starting with the goals and motivations helps ensure your personas will reflect your users' perspectives and not the researchers' perspectives.

We continue filling in other characteristics for each persona according to their goals, and in relation to other characteristics, as shown in Figure 3. At the same time, it is important to constantly compare with other personas when filling in their characteristics, making sure that the personas are distinctive from each other and represent different types of users. Creating personas is a creative art requiring constant comparison. Working and discussing with collaborators who are familiar with your data will help you with face validity as follows: Does this persona feel real? Are they coherent? Do they align well with the data? As phenomenography describes the variation in the data but does not tell you how results in different categories connect to individual users, checking the face validity of the personas with a team member deeply familiar with the interview data is a vital part of this process.

Persona Theme 1 (goal and motivation) Theme 2 (attitudes) Theme 3 (challenges) Theme 4 (needs)

Persona 1 Variation within theme

Persona 2

Persona 3

Persona 4

A good and plausible mix of traits, ideas and needs
Figure 3.

Undergraduate researcher personas

\begin{tabular}{|c|c|c|c|}
\hline Persona & Key Quote & Description & Challenges \\
\hline M & $\begin{array}{l}\text { "I want to see what } \\
\text { it's like." }\end{array}$ & $\begin{array}{l}\text { She has many academic and non-academic } \\
\text { interests, and she is open to many future } \\
\text { career options. She thinks doing research is } \\
\text { somewhat important to scientist. She engages } \\
\text { in research for self-competence and } \\
\text { exploration experience. }\end{array}$ & $\begin{array}{l}\text { Self and time } \\
\text { commitment }\end{array}$ \\
\hline & $\begin{array}{l}\text { "I want to work } \\
\text { with these people." }\end{array}$ & $\begin{array}{l}\text { She has ambivalent physics background, and } \\
\text { she does not commit to physics until having a } \\
\text { great physics class or mentors. Her career } \\
\text { plan is undetermined and open, but she has } \\
\text { some role models. She thinks disciplinary } \\
\text { commitment is significant to scientists. She } \\
\text { joins research group for learning with the } \\
\text { people she likes. }\end{array}$ & $\begin{array}{l}\text { Struggles with } \\
\text { self-efficacy and } \\
\text { belonging feeling }\end{array}$ \\
\hline Louis & $\begin{array}{l}\text { "I want to go to } \\
\text { grad school." }\end{array}$ & $\begin{array}{l}\text { He identifies himself as an aspiring scientist } \\
\text { who is determined on Research - Grad School } \\
\text { - Professional career path. He thinks doing } \\
\text { research is significant to scientists. He } \\
\text { engages in research to learn research skills, } \\
\text { look for research of interest, and get } \\
\text { competent for grad school. }\end{array}$ & $\begin{array}{l}\text { Frustration with } \\
\text { research activity } \\
\text { or disappointment } \\
\text { with self-efficacy }\end{array}$ \\
\hline
\end{tabular}


Crucially, we do two processes simultaneously to build meaningful contexts where personas feel more humanlike: we synthesize across phenomenographic categories at the same time as we elaborate on these categories using ideas and language from the interview participants. For example, one category in the goal and motivation theme could be decontextualized as "changing to adapt to departmental and practical considerations." We can enrich this category as if it was said by a specific plausible person. The Diego persona could say: "My department has a culture and a set of practices around teaching and I want to do it and there is an expectation that I do it too." This elaboration makes the personas lifelike, relatable and understandable so that we as designers can easily make sense of those personas' characteristics.

We do not create personas that mimic real individual people, but instead, we build coherent and plausible human constructs that correspond to our understanding of faculty. We are flexible in distributing characteristics to personas, in abandoning implausible personas and in changing and revising our choices until the personas as a set are a coherent and plausible representation of our data. For example, in this work, we eventually finalized the set of faculty personas to six personas that fully represent the diversity of faculty we interviewed (Figure 4). During this iterative design process, we started with Charlotte as part of Sameer for their similar goal of wanting to change to help students. However, as we elaborated and reflected on the persona's characteristics with our interview data, we decided to separate them to distinguish Charlotte's motivation for large-scale change and Sameer's motivation for smaller-scale change. Charlotte and Sameer's stories corresponding to their new and subtly different motivations make their distinction more plausible (Figure 3 ). In our experience, it is difficult to get to know and work with more than six personas, so we aim to develop four-six personas to describe a set of data.

The second stage in crafting personas is adding details to make the personas feel more like real people. This includes names with short descriptive nicknames, ages, profile pictures, backgrounds, short quotes, etc. Adding these details makes it easier for a design team to remember and refer to each persona, as well as treat them like real people. You can use photos of real people or create avatar-like pictures of people (as used in Figures 4 and 5).

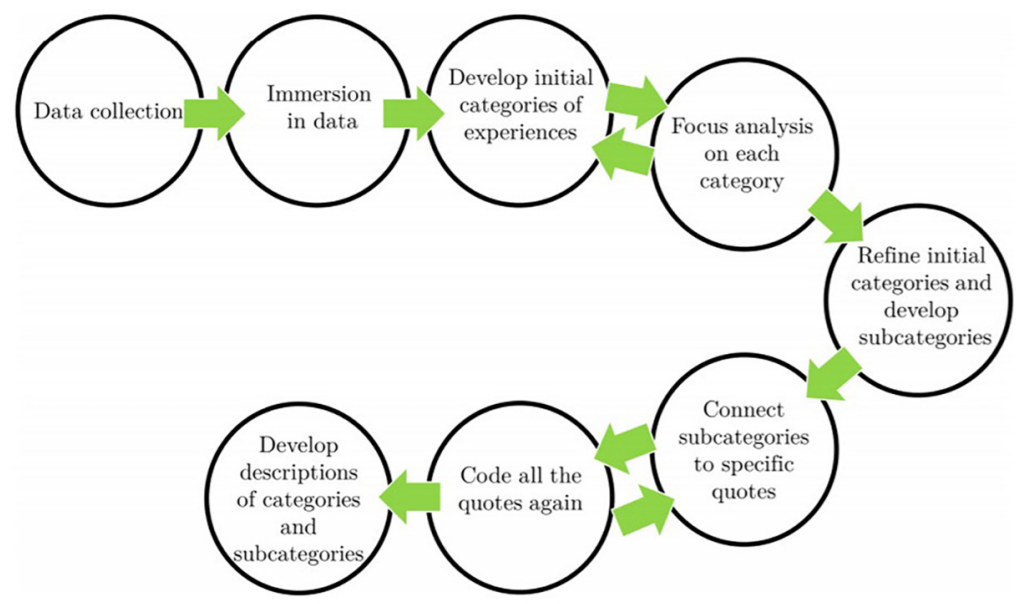

Source: Zohrabi Alaee et al. (2020)
User-centered design in education

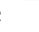




\section{ILS \\ $122,11 / 12$}

700

Figure 5.

Examples of

PhysPort personas

representing

variation in physics

faculty around their

motivations and

attitudes for making

changes to their

teaching

\begin{tabular}{|c|c|c|c|c|c|}
\hline Persona & $\begin{array}{l}\text { Motivation for } \\
\text { trying new things }\end{array}$ & $\begin{array}{l}\text { Attitude } \\
\text { towards } \\
\text { change }\end{array}$ & $\begin{array}{l}\text { Types of things to } \\
\text { try }\end{array}$ & $\begin{array}{l}\text { How they } \\
\text { know if it } \\
\text { works }\end{array}$ & Resources \\
\hline Sameer & $\begin{array}{l}\text { I care a lot about } \\
\text { student learning and } \\
\text { development } \\
\text { including students' } \\
\text { skills, content } \\
\text { knowledge, affect, } \\
\text { identity, etc. Keeping } \\
\text { my students engaged } \\
\text { will support their } \\
\text { learning. }\end{array}$ & $\begin{array}{l}\text { I want to be } \\
\text { continually } \\
\text { improving my } \\
\text { teaching and I'm } \\
\text { really } \\
\text { thoughtful about } \\
\text { my class. I will } \\
\text { try things that } \\
\text { take me a lot of } \\
\text { time and are } \\
\text { hard for me, if I } \\
\text { think that they } \\
\text { will benefit } \\
\text { students. }\end{array}$ & $\begin{array}{l}\text { I want to add a new } \\
\text { teaching method to } \\
\text { my toolbox of } \\
\text { things that I already } \\
\text { do. I'm open to } \\
\text { new big ideas. I } \\
\text { want to broaden my } \\
\text { perspective on } \\
\text { important issues } \\
\text { that influence my } \\
\text { students/classroom. }\end{array}$ & $\begin{array}{l}\text { My students } \\
\text { learn more } \\
\text { and are more } \\
\text { engaged and } \\
\text { it shows in } \\
\text { my student } \\
\text { evaluations, } \\
\text { research- } \\
\text { based } \\
\text { assessment } \\
\text { scores, and } \\
\text { exams. } \\
\text { Evidence is } \\
\text { important! }\end{array}$ & $\begin{array}{l}\text { Everything, } \\
\text { everywhere }\end{array}$ \\
\hline Charlotte & $\begin{array}{l}\text { I see a big problem in } \\
\text { my department: } \\
\text { Drop/Fail/Withdrawal } \\
\text { rates, graduation } \\
\text { rates, major } \\
\text { conversions, learning } \\
\text { gains in intro, etc. I } \\
\text { want to fix it. }\end{array}$ & $\begin{array}{l}\text { This needs to be } \\
\text { done. It's hard } \\
\text { work and it's } \\
\text { important. I } \\
\text { need to build } \\
\text { support in my } \\
\text { department to } \\
\text { do this, possibly } \\
\text { via research } \\
\text { results or } \\
\text { funding } \\
\text { possibilities. }\end{array}$ & $\begin{array}{l}\text { Let's make big } \\
\text { pedagogical or } \\
\text { programmatic } \\
\text { changes that } \\
\text { involve multiple } \\
\text { faculty or courses. }\end{array}$ & $\begin{array}{l}\text { My problem } \\
\text { is better. }\end{array}$ & $\begin{array}{l}\text { I looked in the } \\
\text { literature to find } \\
\text { the most } \\
\text { effective solution } \\
\text { to my problem. } \\
\text { Both pedagogical } \\
\text { articles and } \\
\text { physics education } \\
\text { research ones. I } \\
\text { also ask experts } \\
\text { to help. }\end{array}$ \\
\hline
\end{tabular}

You should carefully consider the benefits and drawbacks of each representation based on your intent. For example, while photos of real people make personas feel more real and memorable, they are often more expensive. Moreover, their bodily expressions and appearances may influence designers' personal emotions and bias toward the users those personas represent.

The creative art in this stage lies in how to portray plausible personas and simultaneously avoid stereotypes that one might have. For example, you can choose portraits which represent a diversity of users and backgrounds, which may help your design team think more inclusively about the people they are designing for. Similarly, when naming the PhysPort personas, we sought to present a diverse set of physics faculty personas to illustrate that all kinds of people can be physics faculty. Each persona's name also alliterates with their epithet, making the personas even more memorable. We sought to avoid gender or ethnic stereotypes when assigning identities to different personas; however, we tried to match names with gender and racial characteristics in the portraits. We shared our named personas and descriptions with colleagues and community members, renaming personas when they pointed out issues that could lead to confusion or bias.

When we finished infusing themes into personas and making them humanlike, we wrote a descriptive paragraph for each persona, a narrative that linked their characteristics to get a full portrait of a human. We designed persona cards so that personas are better assimilated and communicated with the design team, including stakeholders. We present here the six faculty personas (Figure 4) and an example persona card of Claude (Figure 6).

\subsection{Check the personas}

Checking the personas is an important step to scientifically ensure their validity and reliability for further deliberate design. In this case, we need to check our personas' validity by going back and forth between the sets of personas, the real data and the 


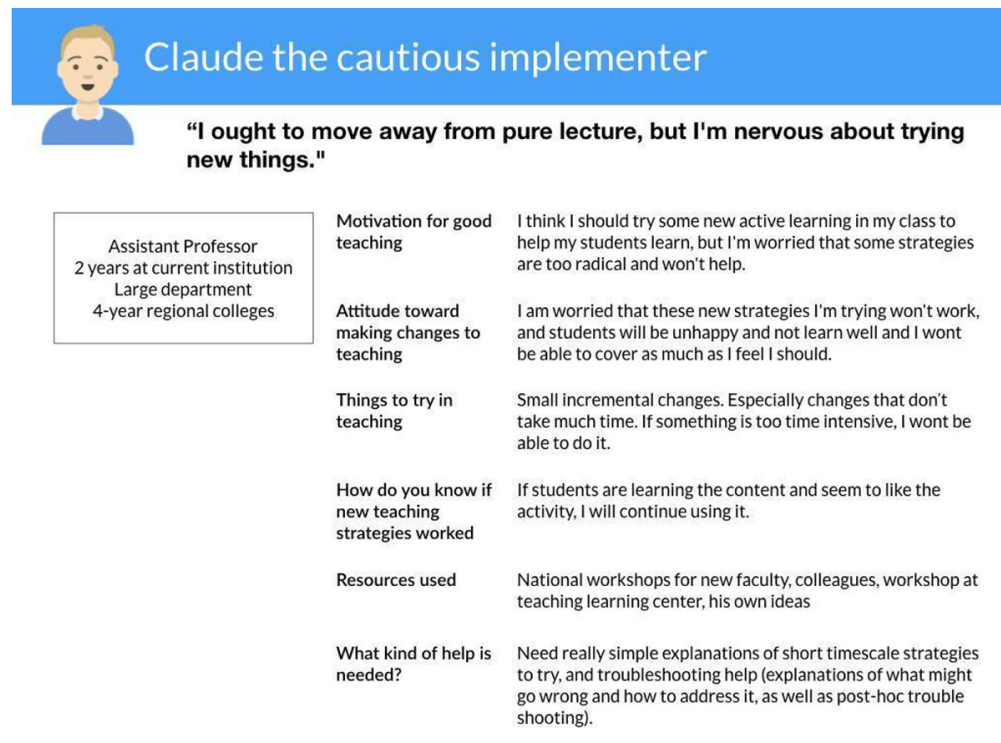

phenomenographic analysis. A valid set of personas is one that covers the whole data set, where every real person from the data is primarily represented by one persona while having a reflection in at least one or a few other personas. For example, the set of 6 faculty personas represent the sample of 23 faculty interviewees as shown in Table 3. In this case, Interviewee 1 is primarily described by the persona Claude (with main motivation, attitude and behaviors) and secondarily described by the persona Suki (with minor experiences). This quality of personas is extremely important for us to effectively represent our interviewed faculty without revealing their individual identities. What is more, we hope that a design solution that is devised mainly with one persona in mind could also benefit other users who have this as their secondary persona. During this process, we are more concerned with creating personas that are distinct from each other and which completely describe the set of potential users than we are with the weight of each persona in the interview data.

Before we discuss using personas to solve PhysPort design problems, we want to address a common concern of designers using personas: losing too many details from our real users at the end of the creation cycle (Figure 7). When conducting phenomenographic analysis, we gain insight into abstractions of individuals' experiences, but we lose some

\begin{tabular}{lllllll}
\hline & Claude & Diego & Suki & Imani & Sameer & Charlotte \\
\hline Interviewee 1 & Primary & Primary & Secondary & & & \\
Interviewee 2 & & Secondary & Primary & $\begin{array}{l}\text { Tertiary } \\
\text { Interviewee 3 }\end{array}$ & Secondary & \\
Interviewee 4 & Secondary & Primary & & Secondary & & \\
Interviewee 5 & & Primary & & &
\end{tabular}

$[\ldots]$

Interviewee 22

Interviewee 23

\section{User-centered design in education}

Figure 6.

Claude persona card

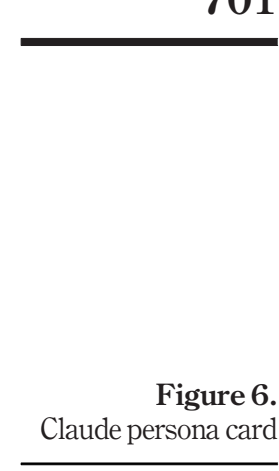




\section{ILS}

$122,11 / 12$

702

Figure 7.

Persona methodology cycle diagram shows the relationships between the three parts of the persona development cycle and how information is gained or lost when moving between Stages 2-5 details that do not fit into our emergent themes. Our goal for the design intentionally influences the themes we decide to prioritize and the details we decide to ignore. From a large group of real stories, a list of important details gets extracted out and synthesized into a much smaller set of personas and we lose the direct link to individuals. When infusing the variation within themes into our cast of relatable personas, we again use our design sense to judge whether a mix of traits is plausible, and hence, we perhaps lose some variation as well. When mapping back to the data, we revive the connection between personas and real people, which is more representative but might not be as descriptive because of the connection to individuals we have broken in the previous step.

In addressing concerns about losing details when building personas, we think this is inevitable. Not all details carry equal weight and it is often practical to lose idiosyncratic details that are irrelevant to the design goals. Different methodologies represent the data for otherwise meaningful purposes. When transferring the information from one methodological representation to another, it is important to ensure that we capture details that are deeply connected to our design goals. In many cases, this process may allow some personas to be too disconnected from representing our real users. Adjusting one persona in a set might impact others' uniqueness. Therefore, revising personas might entail adjusting the whole set of personas, and designers might need to iterate the whole cycle several times to achieve a representative set of personas. This is a common situation and we suggest giving each new iteration of personas new personal information, including new names and images so that earlier draft personas do not affect the process of constructing new ones.

\subsection{Solve the PhysPort design problem}

To use personas in the PhysPort redesign process, we order the personas in design priority. Designers often identify the design priority based on an evaluation of how important serving each persona is to achieve the goals of the design. Design priority guides designers in determining which users' needs should be met first. This may be related to the relative number of potential users associated with each persona, but there may also be cases in which a persona is very important even if that persona does not represent many users. For example, a persona might represent the small number of users who are likely to contribute content to the website, which is important to the project's goal of building the website's resources.

After we have a clear idea of our priorities, we will brainstorm a large number of scenarios that our top prioritized personas would do as a part of teaching their physics courses. For example, we could write out the steps that Claude the cautious implementer would take when revising a lab activity or planning a new course from scratch and how he would use online 
resources (including PhysPort) to help him in this process. Each scenario is written for a particular persona, though similar scenarios featuring different personas are possible. Next, we would prioritize the scenarios according to project goals. From there, we would create a workflow for each high-priority scenario, sketching out the steps of the scenario step by step. Using workflows, we would then design wireframes, which are the actual design of the actual screens. The final step of the design process is to test the wireframes by asking potential users to achieve the goal of the scenario using the wireframes.

User-centered design in education

\section{An example of undergraduate research program design}

Personas are originally used for website-based design problems, but personas can be helpful for understanding users in other contexts as well. In this section, we illustrate that claim through discussing personas for a very different educational design problem undergraduate research programs. Additionally, it can be economical to use archival data for persona generation. We will briefly discuss our process of creating undergraduate researcher personas using archival data about students' engagement with undergraduate research (Huynh et al., 2020).

\subsection{Creating undergraduate researcher personas}

Undergraduate research experiences are beneficial to students across disciplines (Becker, 2005; Laursen et al., 2010). However, most of the tasks we as educators want students to perform are not inherently interesting to them and this includes research practices (Ryan and Deci, 2000). Even when students have some interest in research, their motivations are often extrinsic and various external barriers may challenge their participation. Therefore, while looking to address the design problem of our local department - "How can the physics department engage diverse students into undergraduate research?" we decide to use personas to study undergraduate students' various experiences with the departmental research. We suggest that personas can guide the design of an undergraduate research program that considers the diverse needs, motivations and challenges of undergraduate researchers.

Using archival interview data, we built these personas in a similar manner as we built our faculty personas for PhysPort. The data are drawn from semi-structured interviews with 21 students at Kansas State University physics department (Irving and Sayre, 2014, 2015 , 2016). In these sets of interviews, the discussion usually includes students' interest and experience in physics, their self-perception and physics identity, their perception of physicist identity and their professional and career plans. We decided to use this data as the interview protocol covers our understanding of important aspects of undergraduate researcher experiences. The personas of students engaged in research are built upon the 9 students who engaged in physics research and do not include data from the other 12 students, as they did not participate in physics research.

We conducted a phenomenographic analysis on the interview data. We decided to repurpose phenomenographic studies published on this data set about students' physics identity as we perceived that students' ideas about physics identity strongly connected to their participation in research (Irving and Sayre, 2014, 2015). Using our judgment in concert with examining students' interviews, we also identified additional emergent themes that are relevant to student research engagement. The final list of themes includes college majors and minors, experience with physics, motivation for doing research, physics identity and career plan or awareness of jobs for physics majors. We find that motivation for research engagement strongly influences other behaviors. We explored the variation among the students within each theme. We found three different motivations which suggest the seeds 


\section{ILS \\ $122,11 / 12$}

\section{4}

Table 4.

Worksheet to create personas, starting with filled motivation Persona 3 and goals of three distinct personas (Table 4). We created a spreadsheet with a column for each motivation; bit-by-bit, we filled in each row with variations from other themes, so that each student persona emerged as a distinctively meaningful and plausible construct. More details are added to complete the portrait of each persona, including drawing out scenarios and challenges for each persona, avatar and one short characterizing quote.

Then, we checked the personas' validity by mapping the real students with their primary and secondary representative personas. We also selected a few cases of students who did not engage in research. We checked to see if they had struggles that prevented them from doing research and if their struggles matched the pain points of any of the personas we had developed. The set of personas was then discussed with a group of researchers for peer review and validation, resulting in a set of three undergraduate research personas - Louis, Maria and Ashley (Figure 5).

\subsection{Limitation and benefit of the undergraduate researcher personas}

One limitation of the set of undergraduate researcher personas is that we created them with archival data that were not very diverse, partly because the available population is not very diverse demographically and partly because the interview participants were not originally selected for the diversity of research motivations. With purpose-gathered data, there might be one or more personas representing non-traditional students (older than 25, working fulltime or part-time to support themselves or having dependents) or personas whose motivation in engaging in research is a part-time job opportunity or helping them get better future jobs. Education researchers (Choy, 2002; Wyatt, 2011) have emphasized the important presence and the different needs and motivations of these types of students. With our limited data set, we are likely to miss key information that helps portray this type of undergraduate researcher personas. We recommend that designers couple data collection and constructed personas with other reliable sources, such as delving into relevant literature or seeking expert reviews to ensure the set of personas adequately covers the potential population.

The set of undergraduate researcher personas is potentially helpful to address our design problem in many ways (Huynh et al., 2020). First, personas help us to represent the diverse population of students with various but unique characteristics without exposing students to the risks of revealing their identities. For instance, talking about a particular student via a mix of the personas alleviates this risk without losing important details of their motivation and attitude toward research. Second, with personas, we keep our focus on relevant motivations and behaviors of students to their research activities and we are not distracted by other superfluous details that do not add value to the design. For example, many students shared their experiences and satisfaction with physics courses back in high schools, which we could have included as one emergent theme. These experiences, however, are beyond the scope of our design within the undergraduate program and have inconsistent

\begin{tabular}{llccc}
\hline & $\begin{array}{l}\text { Motivation and goals } \\
\text { toward research }\end{array}$ & $\begin{array}{c}\text { Major/minor and } \\
\text { experience with physics }\end{array}$ & $\begin{array}{c}\text { Physics } \\
\text { identity }\end{array}$ & $\begin{array}{c}\text { Career plans and physics } \\
\text { jobs awareness }\end{array}$ \\
\hline Persona 1 & Try a new experience & - & - & - \\
Persona 2 & Work with favorite & - & - & - \\
Persona 3 & $\begin{array}{l}\text { Gain competence for } \\
\text { grad school }\end{array}$ & - & - & - \\
& & & & - \\
\hline
\end{tabular}


effects on students' participation in research. Therefore, we treated them as irrelevant to the design and decided not to focus on them during the design process. The final focused and personalized program design can effectively support students through what works best for them rather than treating them the same with the assumption and expectation that undergraduate students are all alike.

\section{Implication}

Educational design is an important part of the process of evidence-based education reform, bridging the gap between educational practice and educational research results. Addressing educational design problems requires educators to further take the roles of researchers and designers. In this work, we introduce a design tool - personas - from human-computer interface design that supports user-centered design. User-centered design is increasingly assimilated within the designer community as a perspective that promotes the usability and productivity of the designed product. We adopt the user-centered design, as well as personas, arguing for their power in helping us address our problems of practice - a very different work from the case study and phenomenographic study.

Personas are motive-driven user models. Building personas help us focus on why and how our users use our products so that we can design ones that they need. Personas are a great model to represent our research participants, not only covering large data sets in smaller numbers of relatable humanlike constructs but also protecting participants' identity in communication with other designers and stakeholders. Discussing design features for six personas is certainly more effective than for 23 different real faculty that have been interviewed.

Personas are also great at protecting study participants' identity because of the blended construct of characteristics from many different real people and fictitious details. In this paper, we described an example of building personas of undergraduate researchers. These personas provide faculty with a coherent understanding of undergraduate research students without exposing the identities of particular students in a department. The personas can be used to develop a research program well-matched to undergraduates' motivations. Furthermore, personas can be powerful research tools, especially when researchers study critical and sensitive issues. For example, building personas of students who decide to stay in or withdraw from physics programs due to racist and sexist academic environments will bring data-driven insights into the open discussion of these issues without risking student participants' anonymity because each persona is an amalgamation of the characteristics of several people, not a single person as in a case study. Further, we can create the details of the persona so the people participating in discussions of sensitive issues using the personas do not inaccurately assume they represent a certain real student.

Designing is a deliberate work involving both art and science. The heart of this paper lies in our attempt to clarify this design strategy in both its art and science parts. Even though there are many guidelines for building personas available in interaction design, differences in the nature and approach of education and interaction design make it difficult for educational designers and researchers to follow without certain adjustments. Furthermore, the method of personas is often challenged methodologically. Some of the challenges include the unclear connection between real users and the way data are collected and analyzed, difficulty in implementing and disseminating within the design team and stakeholders, risk of overuse and misuse, etc. (Neilson, 2013; Grudin and Pruitt, 2002; Pruitt and Grudin, 2003; Portigal, 2008). This could contribute to why the use of this powerful tool is still scarce in education. Although we do not aim to address all of the challenges personas are facing, we hope to provide a principled, step-by-step instruction of building validated and reliable sets 


\section{ILS}

$122,11 / 12$

of personas via two problem designs of faculty professional development and student research engagement that education researchers could find helpful and supportive. Yet, more work is needed to further focus on the implementation of personas in education research and design, including integrating personas with other design tools such as scenarios, user case and usability testing to support effective user-centered design.

Because personas are built upon users' motivation or goals, which varies with the product, personas are not complete or generic, but rather directly dependent on the context and the problem designs. Therefore, for a similar problem design, we might expect a different set of personas. Even though it is common in design that different departments sometimes find the same set of personas useful, we recommend that using personas from different contexts requires careful consideration and adjustment.

\section{Note}

1. Portions of this work appeared in an earlier form in the first author's doctoral dissertation (Huynh, 2020).

\section{References}

Becker, K. (2005), "Cutting-edge research by undergraduates on a shoestring?", Journal of Computing Sciences in Colleges, Vol. 21 No. 1, pp. 160-168.

Blomkvist, S. (2007), The User as a Personality. A Reflection in the Theoretical and Practical Use of Personas in HCI Design, Uppsala University, Uppsala.

Choy, S. (2002), Nontraditional Undergraduates: Findings from the Condition of Education 2002, US Department of Education, National Center for Education Statistics, Washington, DC.

Cooper, A. (1999), The Inmates Are Running the Asylum, Macmillan Publishing, Indianapolis, IN, 10.1007/978-3-322-99786-9_1.

Cooper, A., Reimann, R. and Cronin, D. (2007), About Face 3: The Essentials of Interaction Design, John Wiley and Sons, New York, NY.

Creswell, J.W. (2007), "Five qualitative approaches to inquiry", Qualitative Inquiry and Research Design: Choosing among Five Approaches, 2nd ed., SAGE Publications, Thousand Oaks, CA, pp. 53-80.

Crossley, L. (2003), "Building emotions in design”, The Design Journal, Vol. 6 No. 3, pp. 35-45. No

Endsley, M.R. (2016), Designing for Situation Awareness: An Approach to User-Centered Design, CRC Press, Boca Raton, FL.

Goodwin, K. (2002), "Getting from research to personas: harnessing the power of data", Cooper Newsletter, available at: https://articles.uie.com/research_to_personas/ (accessed 18 May 2021).

Grudin, J. and Pruitt, J. (2002), "Personas, participatory design and product development: an infrastructure for engagement", in Binder, T., Gregory, J. and Wagner, I. (Eds), Proceedings of Participation and Design Conference (PDC2002), Malmö, Sweden, pp. 144-161.

Huynh, T. (2020), "Professional development of physics faculty and undergraduate students", $\mathrm{PhD}$ diss.

Huynh, T., Madsen, A.M. and Sayre, E.C. (2020), "Undergraduate researcher personas", in Gresalfi, M. and Horn, I.S. (Eds), Proceedings of the 2020 International Conference of the Learning Sciences, Nashville, TN, pp. 1157-1560.

Irving, P.W. and Sayre, E.C. (2014), "Upper-Level physics students' perceptions of physicists", Proceedings of the 2014 International Conference of the Learning Sciences, Boulder, CO, Vol. 3, pp. 1513-1514.

Irving, P.W. and Sayre, E.C. (2015), "Becoming a physicist: the roles of research, mindsets, and milestones in upper-division student perceptions", Physical Review Special Topics-Physics Education Research, Vol. 11 No. 2, p. 020120, doi: 10.1103/physrevstper.11.020120. 
Irving, P.W. and Sayre, E.C. (2016), "Identity statuses in upper-division physics students", Cultural Studies of Science Education, Vol. 11 No. 4, pp. 1155-1200.

Kozar, K. and Miaskiewicz, T. (2009), "Designing the introductory is course using student personas: lessons learned from product design”, AMCIS 2009 Proceedings, p. 454, available at: https:// aisel.aisnet.org/amcis2009/454/ (accessed 18 May 2021).

Laursen, S., Hunter, A.B., Seymour, E., Thiry, H. and Melton, G. (2010), Undergraduate Research in the Sciences: engaging Students in Real Science, John Wiley and Sons, New York, NY.

Long, F. (2009), "Real or imaginary: the effectiveness of using personas in product design", in Dockrell, S., Ward, M., Grimes, T., McCaughan, C., Leva, C. and O'Sullivan, L.W. (Eds), Proceedings of the Irish Ergonomics Society Annual Conference, Vol. 14, pp. 1-10.

McKagan, S.B., Strubbe, L.E., Barbato, L.J., Mason, B.A., Madsen, A.M. and Sayre, E.C. (2020), "PhysPort use and growth: supporting physics teaching with research-based resources since 2011", The Physics Teacher, Vol. 58 No. 7, pp. 465-469.

Madsen, A., McKagan, S.B., Sayre, E.C., Martinuk, M. and Bell, A. (2014), "Personas as a powerful methodology to design targeted professional development resources", Proceedings of the 2014 International Conference of the Learning Sciences, Boulder, CO, Vol. 2, pp. 1082-1086.

Madsen, A.M., McKagan, S.B., Strubbe, L.E., Sayre, E.C., Alaee, D.Z. and Huynh, T. (2019), "Usercentered personas for PhysPort", Paper presented at the Physics Education Research Conference Proceedings (PERC), 24-25 July, Provo, UT, available at: https://www.compadre.org/portal/ document/ServeFile.cfm?ID=15295\&DocID=5207 (accessed 12 July 2020).

Maier, R. and Thalmann, S. (2010), "Using personas for designing knowledge and learning services: results of an ethnographically informed study", International Journal of Technology Enhanced Learning, Vol. 2 Nos 1/2, pp. 58-74.

Marton, F. (1986), "Phenomenography-a research approach to investigating different understandings of reality", Journal of Thought, pp. 28-49.

Mulder, S. and Yaar, Z. (2006), The User is Always Right: A Practical Guide to Creating and Using Personas for the Web, New Riders, Indianapolis, IN.

Nielsen, L. (2013), Personas - User Focused Design, Springer, London, pp. 59-79, doi:10.1007/978-1-44714084-9_12.

Norman, D. (2013), The Design of Everyday Things: Revised and Expanded Edition, Basic Books, New York, NY.

Polkinghorne, D.E. (1989), "Phenomenological research methods", in Valle, R.S. and Halling, S. (Eds), Existential-Phenomenological Perspectives in Psychology, Springer, Boston, MA, pp. 41-60, doi:10.1007/978-1-4615-6989-3_3.

Portigal, S. (2008), “TRUE TALES persona non grata”, Interactions, Vol. 15 No. 1, pp. $72-73$.

Pruitt, J. and Adlin, T. (2010), The Persona Lifecycle: keeping People in Mind throughout Product Design, Elsevier, San Francisco, CA.

Pruitt, J. and Grudin, J. (2003), "Personas: practice and theory", DUX '03: Proceedings of the 2003 Conference on Designing for User Experiences, San Francisco, CA, pp. 1-15.

Ryan, R.M. and Deci, E.L. (2000), "Intrinsic and extrinsic motivations: classic definitions and new directions", Contemporary Educational Psychology, Vol. 25 No. 1, pp. 54-67.

Salomão, R.C.S., Rebelo, F. and Rodríguez, F.G. (2015), "Defining personas of university students for the development of a digital educational game to learn Portuguese as a foreing language", Procedia Manufacturing, Vol. 3, pp. 6214-6222.

Stefaniak, J.E. (2020), "8 Ethnographic consideration within instructional design research practices", Research Methods in Learning Design and Technology, p. 111, available at: https://doi.org/ $10.4324 \% 2 F 9780429260919-8$ (accessed 18 May 2021). 


\section{ILS}

$122,11 / 12$

Strubbe, L.E., Madsen, A.M., McKagan, S.B. and Sayre, E.C. (2020), "PhysPort as professional development to foster creativity in teaching", Paper presented at the Physics Education Research Conference Proceedings (PERC) 2020, available at: https://doi.org/10.1119\% 2Fperc.2020.pr.strubbe (accessed 18 May 2021).

Wyatt, L.G. (2011), "Nontraditional student engagement: increasing adult student success and retention", The Journal of Continuing Higher Education, Vol. 59 No. 1, pp. 10-20.

Zagallo, P., McCourt, J., Idsardi, R., Smith, M.K., Urban-Lurain, M., Andrews, T.C., Haudek, K., Knight, J.K., Merrill, J., Nehm, R. and Prevost, L.B. (2019), "Through the eyes of faculty: Using personas as a tool for learner-centered professional development", Schussler, E. (Ed.), CBE-Life Sciences Education, Vol. 18 No. 4, pp. 18:ar62, 1-21.

Zohrabi Alaee, D., Strubbe, L.E., Sayre, E.C., Madsen, A.M. and McKagan, S.B. (2020), "Phenomenographic study of physics instructor's instructional change", Working paper, Department of Physics, Kansas State University, Manhattan, KS, 12 July.

\section{Further reading}

Gay, G. and Hembrooke, H. (2004), Activity-Centered Design: An Ecological Approach to Designing Smart Tools and Usable Systems, MIT Press, Cambridge, MA.

Henderson, C. and Dancy, M.H. (2008), "Physics faculty and educational researchers: divergent expectations as barriers to the diffusion of innovations", American Journal of Physics, Vol. 76 No. 1, pp. 79-91.

Hunter, A.B., Laursen, S.L. and Seymour, E. (2007), "Becoming a scientist: the role of undergraduate research in students' cognitive, personal, and professional development", Science Education, Vol. 91 No. 1, pp. 36-74.

Ward, K. (2005), "Research with undergraduates: a survey of best practices", Journal of Computing Sciences in Colleges, Vol. 21 No. 1, pp. 169-176.

Zaugg, H. and Rackham, S. (2016), "Identification and development of patron personas for an academic library", Performance Measurement and Metrics, Vol. 17 No. 2, pp. 124-133.

\section{Corresponding author}

Eleanor Sayre can be contacted at: esayre@gmail.com

For instructions on how to order reprints of this article, please visit our website: 